The following poem was written by Marcia Urdang while she recovered from surgery for Crohn's disease

\title{
The human body, a machine of grace
}

The human body, a machine of grace

In step and time, working in total control.

The inner workings, the clock behind the face.

This machine, however, does possess a soul.

Each body unique in its own.

Nerves and muscles working like the strings of a marionette,

A working unit that can be trained and sculpted like stone.

But if abused can cause regret.

The mind must set goals to survive

But the body can set limits unforeseen.

It requires energy as fuel to be alive.

Malnourished, it functions like a horrible dream.

Every piece of equipment is relied upon to grind

And yet, this graceful machine functions only to sustain the mind. 


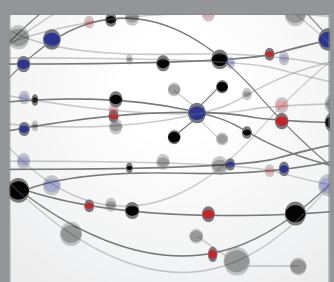

The Scientific World Journal
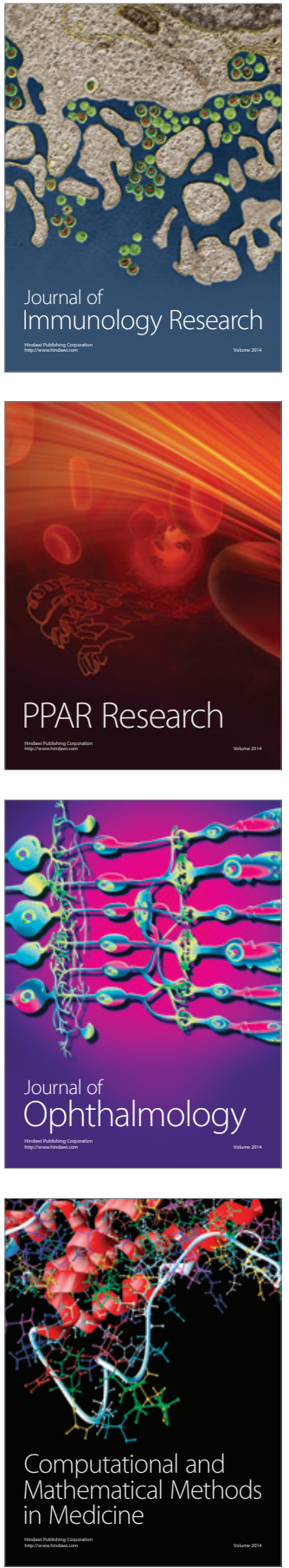

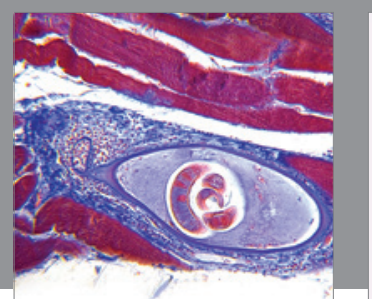

Gastroenterology Research and Practice

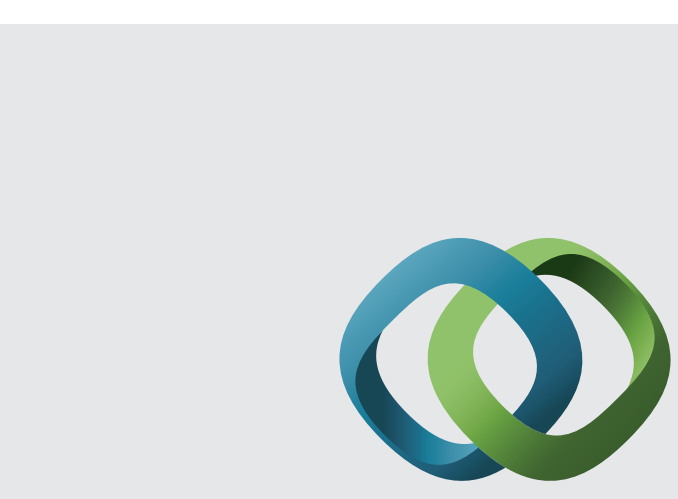

\section{Hindawi}

Submit your manuscripts at

http://www.hindawi.com
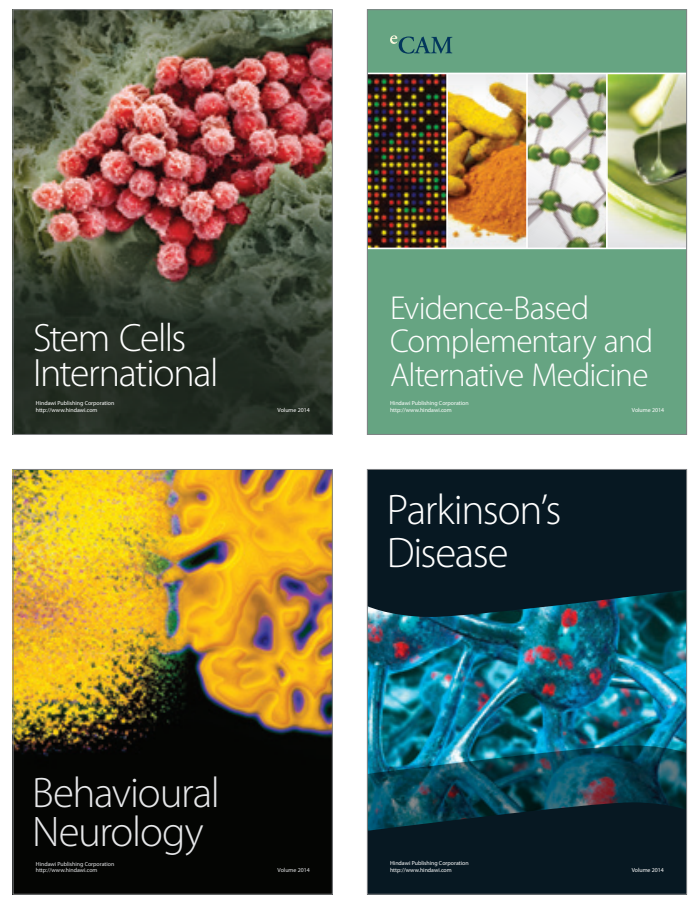
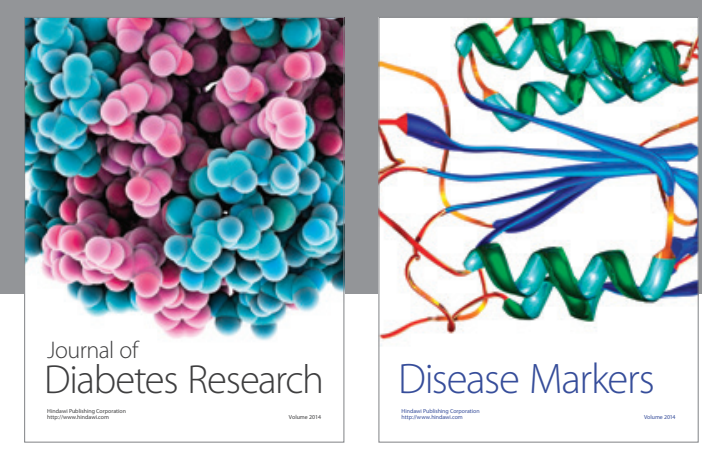

Disease Markers
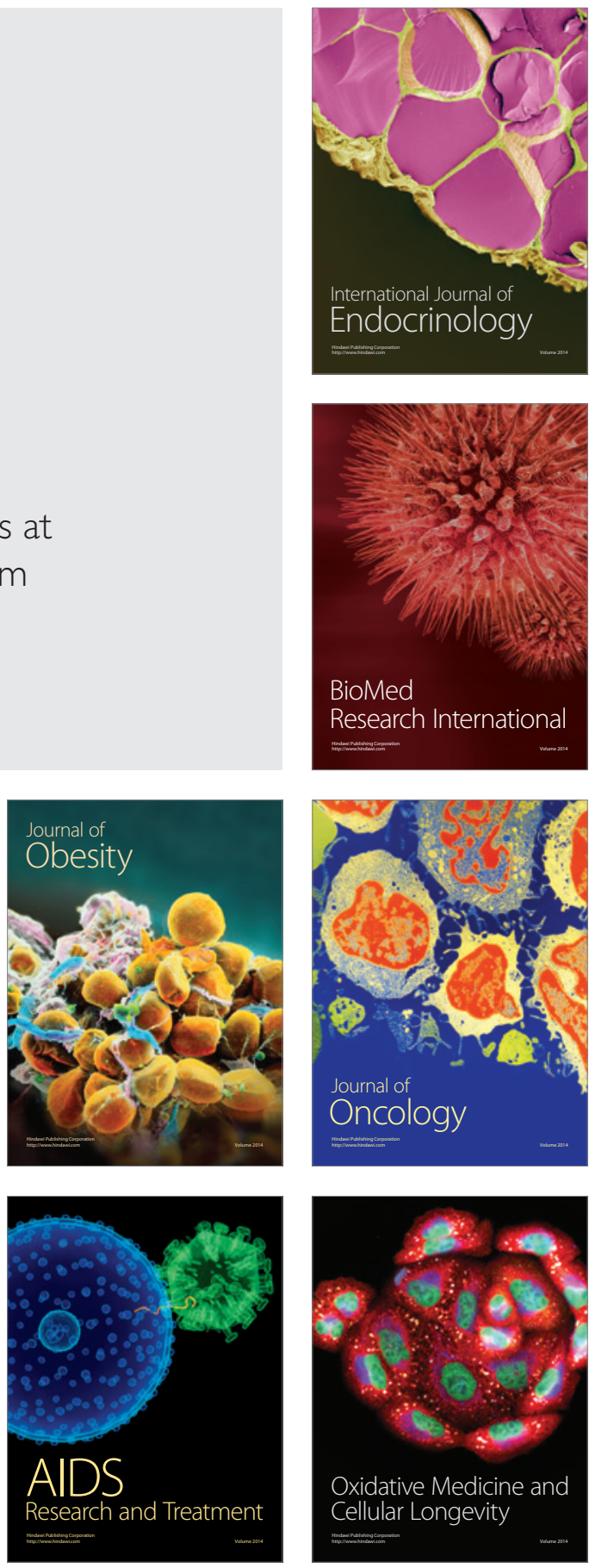